\title{
Optical and morphological investigation of aluminium and nickel oxide composite films deposited by spray pyrolysis method as a basis of solar thermal absorber
}

\author{
A BAGHERI KHATIBANI ${ }^{1}$ and S M ROZATI ${ }^{2, *}$ \\ ${ }^{1}$ Nano Resarch Lab, Lahijan Branch, Islamic Azad University, P.O. Box 1616, Lahijan, Iran \\ ${ }^{2}$ Physics Department, Faculty of Science, University of Guilan, Rasht 41335, Iran
}

MS received 27 January 2014; revised 18 May 2014

\begin{abstract}
Applications of alumina and nickel oxide in various fields specially in solar energy conversion technology encouraged us to study physical properties of such materials. Hence after the deposition of the thin films on glass substrate by spray pyrolysis, using X-ray diffraction (XRD), scanning electron microscopy (SEM), and UV-visible spectrophotometry, various physical properties were investigated. Different optical quantities such as optical band gap, refractive index, extinction coefficient, dielectric constants, volume and surface energy loss functions and optical conductivity were determined. Within this paper for different nickel to aluminium ratio (from 20/80 to 80/20 ratio) at specific substrate temperatures $\left(300^{\circ} \mathrm{C}\right)$, decrease of optical transmittance with nickel content was notable. Using the transmittance data, other optical quantities were achieved by a numerical approximation method. We also observed an increase in the volume energy loss (VELF) more than the surface energy loss (SELF) and simultaneously a decrease trend prevailed according to nickel amount. On the basic of the XRD results, the amorphous phase changed by the presence of more nickel and according to SEM, more obvious nanosized spherical grains at higher nickel ratios can be observed.
\end{abstract}

Keywords. Optical properties; surface properties; composite materials; Urbach energy; electron microscopy.

\section{Introduction}

The optical properties of thin films are very important especially for their applications, e.g., antireflection coatings, integrated optics, solar power engineering, microelectronics and optical sensor technology depending on the reflectance and transmittance properties of the films. ${ }^{1}$ Therefore, preparing a mixture of semiconductor and dielectric materials together and investigating their optical properties may be interesting.

Aluminium oxide, commonly known as alumina, is a widely used material in the family of engineering ceramics. Alumina as a dielectric material posseses excellent properties, ${ }^{2}$ such as high thermal conductivity, low permeability of alkali ions, high hardness, ${ }^{3}$ high chemical and thermal stability ${ }^{4}$ and high radiation resistance. ${ }^{3}$ Alumina thin films have a wide range of applications such as refractory coatings, antireflection coatings, anticorrosive coatings, ${ }^{5}$ microelectronic devices, capacitance humidity sensors, VLSI applications, ${ }^{6}$ water-repellent coating, ${ }^{7}$ waveguide lasers, buffer layers for superconductors, ${ }^{2}$ organic light-emitting devices (OLED), solar selective coatings, bar code readers, optical lenses and windows. ${ }^{8}$

Nickel oxide (NiO) is a semitransparent $p$-type semiconductor material. ${ }^{9}$ It has an energy gap of $3.4-3.8 \mathrm{eV}$ with

\footnotetext{
*Author for correspondence (smrozati@guilan.ac.ir)
}

grey colouration. It represents attractive optical, magnetic, ${ }^{10}$ electric, ${ }^{11}$ electrochromic, ${ }^{12}$ thermo-electric ${ }^{13}$ properties as well as high chemical resistance ${ }^{14}$ among various applications like as gas sensors, ${ }^{15}$ smart windows, ${ }^{14} \mathrm{UV}$ detection, ${ }^{16}$ anti-ferromagnetic materials, ${ }^{17}$ fuel cell, ${ }^{18}$ solar thermal absorber, ${ }^{19}$ transparent electrode, ${ }^{20}$ catalyst for oxygen evolution $^{21}$ and photoelectrolysis. ${ }^{22}$

Alumina and nickel oxide thin films can be deposited by several techniques such as chemical vapour deposition (CVD), ${ }^{23,24}$ spray pyrolysis, ${ }^{25,26}$ electron beam evaporation, ${ }^{27,28}$ magnetron sputtering, ${ }^{29,30}$ anodization, ${ }^{31,32}$ sol-gel, ${ }^{33,34}$ pulsed laser deposition, ${ }^{35,36}$ atomic layer deposition (ALD). ${ }^{37,38}$ Among the different methods for film deposition, spray pyrolysis is suitable for the preparation of efficient, time-resistant and inexpensive thin films. ${ }^{2}$ It is very simple, low $\cos ^{39}$ and does not require vacuum or exotic gas. In this method, fine droplets react on the heated substrate, owing to the pyrolytic decomposition of the solution. The hot substrate provides the thermal energy for the thermal decomposition and subsequent recombination of the constituent species. The phenomenon for the preparation of a metal oxide thin film depends on surface hydrolysis of metal salt on a heated substrate surface..$^{40}$ Thus, the substrate temperature, carrier gas flow, substrate rotating speed, number of spraying sequences, spraying distance, solution flow rate and molarity play an important role in forming the structure of the films ranging from amorphous to crystalline..$^{41,42}$ 
In this report we have prepared aluminium and nickel oxides composite thin films in different molarities onto a glass substrate by spray pyrolysis (SP). The optical and morphological properties, e.g., transmittance, band gap, refractive index, extinction coefficient, dielectric constants, surface and volume energy loss and optical conductivity were investigated for obtaining a greater understanding of such structures.

\section{Experimental}

Our SP device is an experimental apparatus (SCS 90, made by Modern Technology Development Co., Iran) which consists of a spraying unit including a swivel stainless steel (ss) plate over the heater for rotation and heat treatment of substrate. It also has a moving (up and down and rotative) nozzle unit with its controlling tools (e.g., velocity, distance, pressure, aperture diameter, etc.), solution time controller and compressor.

Our optimized values are as follow: The nozzle-substrate distance $(H=34.5 \mathrm{~cm})$, the carrier gas pressure (air, $p=1.5$ bar) and the substrate temperature $300^{\circ} \mathrm{C}$, these conditions as well as the substrate rotation speed and nozzle aperture diameter are fixed.

Aqueous alcoholic solutions of $\mathrm{AlCl}_{3}$ (98\%, Merck) and $\mathrm{NiCl}_{2} \cdot 6 \mathrm{H}_{2} \mathrm{O}(97 \%$, Chem-Lab) were used as precursors for the alumina and nickel oxide thin films in preparation. Deionized water (W) and absolute ethanol $\left(\mathrm{C}_{2} \mathrm{H}_{5} \mathrm{OH}\right.$, $99.9 \%$, Merck) were used as solvents (water: ethanol = $1: 1$, in volumes). The main precursor solutions had 0.25 mol $1^{-1}$ concentration and nickel content (mole percentage of nickel ions to metallic ions) were altered as $20 \%, 40 \%, 60 \%$, $80 \%$. Finally, the solution was sprayed perpendicularly onto preheated glass substrates at $300^{\circ} \mathrm{C}$ which was previously immersed in $\mathrm{HNO}_{3} 10 \%$ solution for $24 \mathrm{~h}$ and then cleaned with acetone and dry air.

Optical transmission for samples measured with a Varian Cary 100 UV/visible spectrophotometer. Thickness measurement of films was done by Dektak system. The optical constants of the films were calculated using the pointwise unconstrained minimization approach (PUMA). ${ }^{43}$ The surface morphology was observed using a scanning electron microscope (SEM) HITACHI S4160.

For easier refer to the samples, they are abbreviated as shown in table 1.

\section{Results and discussion}

To investigate the optical properties of thin films, transmittance spectra for all films were analysed. A good similarity

Table 1. Samples names.

\begin{tabular}{lcccc}
\hline Nickel to aluminium ratio & $20 / 80$ & $40 / 60$ & $60 / 40$ & $80 / 20$ \\
\hline Sample name & S1 & S2 & S3 & S4 \\
\hline
\end{tabular}

exists between the measured spectra and PUMA calculations (figure 1). The PUMA software implements an unconstrained formulation of the nonlinear programming model using a method based on repeated calls to a recently introduced unconstrained minimization algorithm. This method implements the complex optical equations, derived and formulated by Heavens ${ }^{44}$ and Swanepoel. ${ }^{45}$ By PUMA, important parameters such as refractive index $n$, extinction coefficient $k$, the film thickness $d$ and an optimized transmittance can be obtained. Although an initial guess of thickness should be considered until a reliable results is achieved. We have acquired them by Dektak Profilometer as mentioned before and listed in table 2. By above information, other parameters such as band gap $E_{\mathrm{g}}$, Urbach energy $E_{\mathrm{U}}$, dielectric constants $\varepsilon_{1}, \varepsilon_{2}$, volume and surface energy loss function and optical conductivity can be estimated.

According to figure 1, by increasing the nickel content, the transmittance of the films reduced. Although alumina is known as a good absorber by itself, ${ }^{46}$ but it seems that two factors affect the transmittance and make the reduction trend justifiable. In one hand, thickness and packing density of the films have an inverse relationship with transmittance ${ }^{47}$ and on the other hand, the presence of the nickel particles would increase absorptance. ${ }^{48}$ Our reflectance data (not reported here) had also such trend (decrease form by nickel increase)

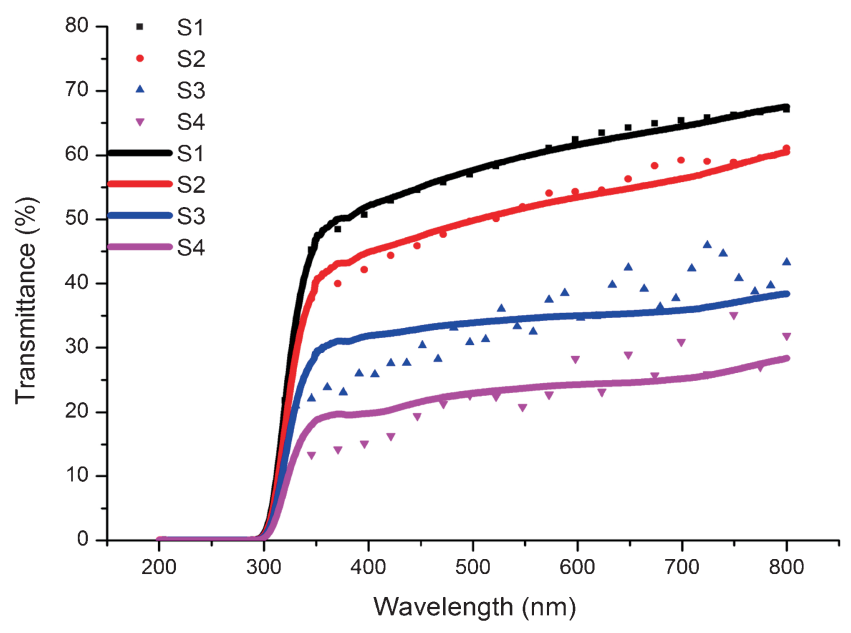

Figure 1. Experimental and estimated optical transmission spectra for thin films (geometric shapes and solid lines for simulated and measured values respectively.

Table 2. Measured and estimated values of thickness for thin films and their transmittance.

\begin{tabular}{lccc}
\hline Sample & $\begin{array}{c}\text { Measured values } \\
\text { of thickness (nm) }\end{array}$ & $\begin{array}{c}\text { Estimated values } \\
\text { of thickness }(\mathrm{nm})\end{array}$ & $\begin{array}{c}\text { Transmittance } \\
(\%)\end{array}$ \\
\hline S1 & 349 & 346 & 60 \\
S2 & 957 & 955 & 52 \\
S3 & 1151 & 1151 & 35 \\
S4 & 1432 & 1430 & 24 \\
\hline
\end{tabular}


that verify our claim. This is suitable for special applications such as solar-selective absorber.

The optical energy gap values depend in general on the structure of the films. The absorption coefficient and the incident photon energy are related by the equation

$$
(\alpha h v)=A\left(h v-E_{\mathrm{g}}\right)^{N},
$$

where $\alpha$ is the absorption coefficient, $A$ the constant, $E_{\mathrm{g}}$ the band gap of the material and the exponent $N$ depends on the type of transition. $N=1 / 2,2,3 / 2,3$ corresponding to allowed direct, allowed indirect, forbidden direct and forbidden indirect, respectively. ${ }^{49}$ There are several relations to evaluate absorption coefficient, ${ }^{45,50}$ such as

$$
\alpha=-\frac{1}{d} \ln \left(\frac{(n+1)^{3}\left(n+s^{2}\right)}{16 n^{2} s} T\right) \text {, }
$$

where $d, n, s$ and $T$ are the thickness, the refractive index of the film, the refractive index of the substrate and transmittance spectrum, respectively.

The determination of $E_{\mathrm{g}}$ was made by extrapolating the linear portion of the curves until they intercept the photon energy axis. The allowed direct transition band gap values (are shown in figure 2) are varied between $3.65 \mathrm{eV}$ (for S1) and $3.93 \mathrm{eV}$ (for $\mathrm{S} 4$ ), hence an increase trend is prevailed by the nickel content.

In the region between the weak absorption tail and the strong absorption region (Tauc region), the optical absorption coefficient follows Urbach rule. ${ }^{51}$ The absorption coefficient shows an exponential energy dependence, referred to as the Urbach tail: ${ }^{52}$

$$
\alpha=\alpha_{0} \exp \left(\frac{h v}{E_{\mathrm{U}}}\right),
$$

where $\alpha_{0}$ is the constant and $E_{\mathrm{U}}$ determines the width of the tail. The Urbach energy, is generally attributed to disorder in the material that leads to a tail in the valence and conduction bands. Figure 3 shows the variation of $\operatorname{Ln} \alpha v s$. $h v$ for the

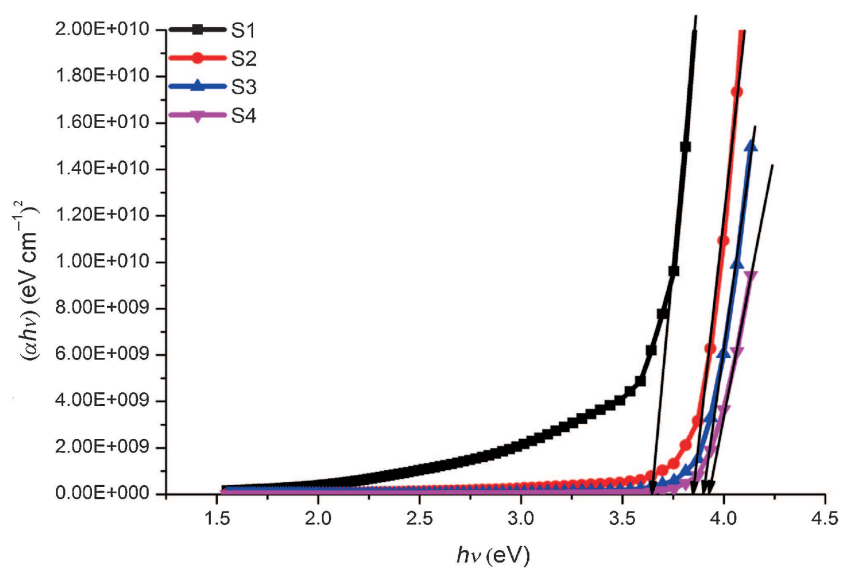

Figure 2. Determination of the optical band gaps from the plots of $(\alpha h v)^{2} v s$. photon energy $h v$. thin films. From the inverse of the slope of the diagram, the values of $E_{\mathrm{U}}$ can be obtained. The relevant values are given in table 3 .

It is obvious from the results that the $E_{\mathrm{U}}$ values change inversely with direct optical band gaps of the films. It can be related to formation of defects during thin films preparation. These defects produce localized states in the films. Thus, the increase in width of the localized states in the optical band gap decreases the optical band gap. ${ }^{53}$

The width of the edge $E_{\mathrm{U}}$, is also related to another parameter which is the slope of the Urbach edge, ${ }^{54}$ and is obtained by

$$
\sigma_{\mathrm{U}}=\frac{K_{\mathrm{B}} t}{E_{\mathrm{U}}}
$$

where $K_{\mathrm{B}}$ is Boltzmann's constant and $t$ the temperature. The steepness parameter $\sigma_{\mathrm{U}}$, value was calculated using $t=$ $300 \mathrm{~K}$ and is brought in table 3 .

Optical constants (i.e., refractive index and extinction coefficient) are important parameters since they determine how a material responds to an electromagnetic field. In the present study, the refractive index, the extinction coefficient and their relevant quantities (such as dielectric constants) of the films have been calculated by PUMA. Of course a fitting of the data to Cauchy's equation was performed after the determination of refractive index and extinction coefficient. This method is highly reliable even in the case of absorbing films or of films that show no fringe pattern in their optical transmission. ${ }^{55}$

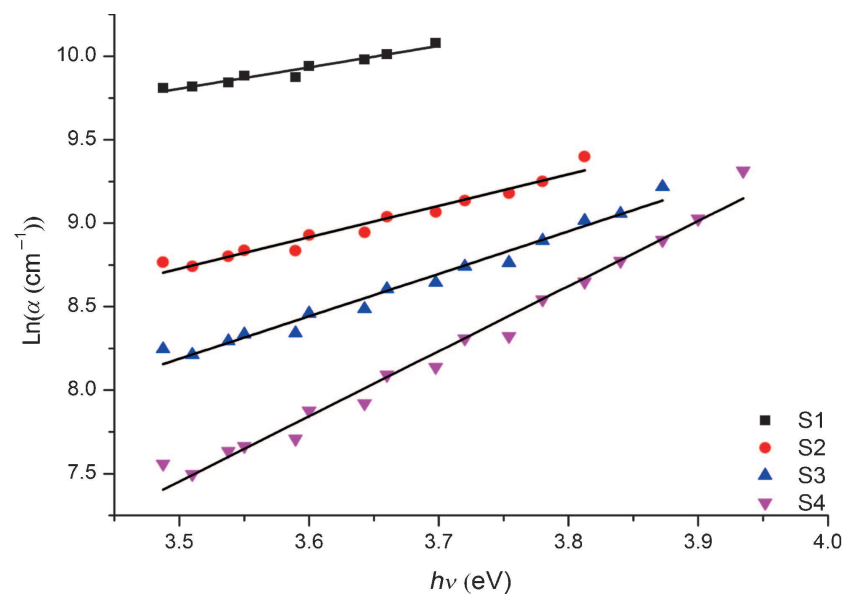

Figure 3. The plots of $\operatorname{Ln} \alpha v s . h v$ for thin films.

Table 3. The optical band gap $E_{\mathrm{g}}$, Urbach tail $E_{\mathrm{U}}$ and steepness parameter $\sigma_{\mathrm{U}}$

\begin{tabular}{lccc}
\hline Sample & $E_{\mathrm{g}}(\mathrm{eV})$ & $E_{\mathrm{U}}(\mathrm{eV})$ & $\sigma_{\mathrm{U}}$ \\
\hline S1 & 3.65 & 0.780 & 0.033 \\
S2 & 3.85 & 0.531 & 0.049 \\
S3 & 3.90 & 0.393 & 0.066 \\
S4 & 3.93 & 0.256 & 0.101 \\
\hline
\end{tabular}


The influence of the compositional ratio of nickel on the refractive index and the extinction coefficient of the films are presented in figure 4. By comparing the refractive index and considering the incremental trend with nickel increase, there would be a reason for the presence of more nickel oxide contribution than the alumina in higher nickel content, if our criterion is proximity to the bulk value or values which obtained by other researchers. ${ }^{1,56}$ The variation of the refractive index presents some interactions between photons and electrons in the material. The refractive index for long wavelengths is a smoothly decreasing function with increasing of wavelength without peaks, as shown in figure 4. This decrease in the refractive index can be associated with fundamental band gap absorption. ${ }^{54}$ Meanwhile the refractive index of the films varies inversely with transmission data. The high (low) transmittance spectra have low (high) refractive index. ${ }^{57}$

Extinction coefficient reflects the absorption of electromagnetic waves due to inelastic scattering events such as the Compton effect, photoelectric effect, pair production effect and so on. ${ }^{58}$ Despite an initial decrease, an increase trend is observed in extinction values. Although the differences is not significant but they are significantly higher than the pure alumina films ${ }^{4,42,43}$ which shows the role of nickel particles in absorptance enhancement.

It was assumed that materials with a higher extinction coefficient are better absorbers, as the extinction coefficient of pure alumina is trivial and the difference between their values in our samples is tiny, it seems absorptance depends on higher refractive index ${ }^{59}$ in agreement with our transmittance spectra and absorption coefficient relation, Relation (1).

The values of refractive index and extinction coefficient at $550 \mathrm{~nm}$ are listed in table 4.

The polarizabiltiy of any solid is proportional to its dielectric constants and their variation with photon energy is an indicative of the interactions between photons and electrons in the films in the energy range.

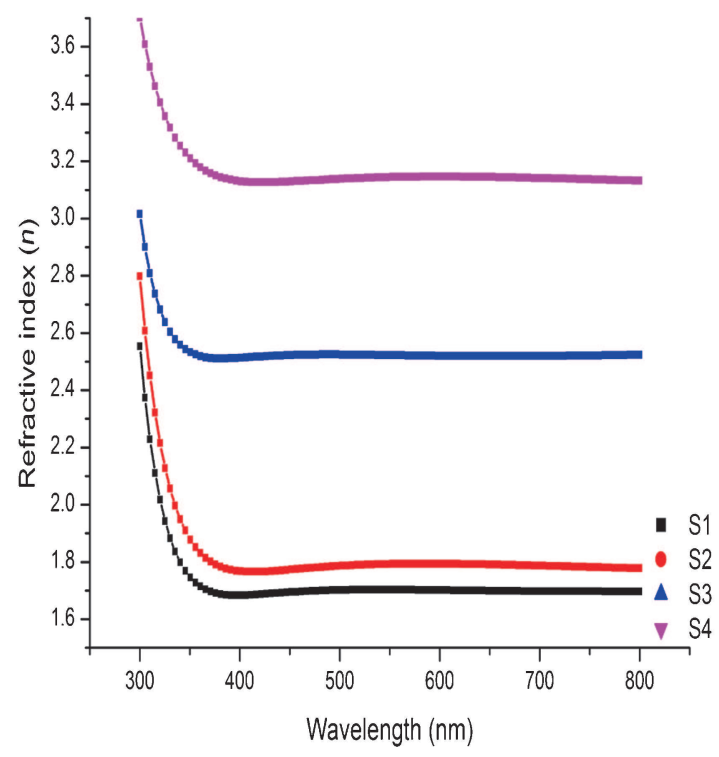

The real and imaginary parts of the complex dielectric constant are expressed as ${ }^{60}$

$$
\varepsilon_{1}=n^{2}-k^{2} \text { and } \varepsilon_{2}=2 n k,
$$

where $\varepsilon_{1}$ and $\varepsilon_{2}$ are the real and imaginary parts of the dielectric constant, respectively. The variation of $\varepsilon_{1}$ and $\varepsilon_{2}$ values of the samples with photon energy are shown in figure 5 and listed in table 4 . The $\varepsilon_{1}$ and $\varepsilon_{2}$ values are analogous to corresponding complex refractive index (real part $n$ and imaginary part $k$ ), since according to Relation (5), $\varepsilon_{1}$ depends on the square of $n$ (subtraction is negligible), whereas $\varepsilon_{2}$ is related to multiplication of $n$ and $k$. For this, the real parts of the dielectric constant are higher than that of the imaginary parts of the dielectric constant.

According to table 4, by increasing the nickel content, the relative increase would be observable, so that a minimum value of 2.89 and a maximum value of 9.89 (for real part of dielectric function) are appeared between them. The real part is important, especially in microelectronic applications. $^{5}$

The inelastic scattering process on a surface, where energy quanta are transferred to or from the topmost atomic layers of solid, yields information about possible excitation of a

Table 4. The refractive index, extinction coefficient and dielectric constants values of the samples at wavelength of $550 \mathrm{~nm}$.

\begin{tabular}{lcccc}
\hline Sample & $\begin{array}{c}\text { Refractive } \\
\text { index }\end{array}$ & $\begin{array}{c}\text { Extinction } \\
\text { coefficient }\end{array}$ & $\begin{array}{c}\text { Real part of } \\
\text { the dielectric } \\
\text { constant }\end{array}$ & $\begin{array}{c}\text { Imaginary part } \\
\text { of the dielectric } \\
\text { constant }\end{array}$ \\
\hline S1 & 1.70 & 0.049 & 2.89 & 0.16 \\
S2 & 1.79 & 0.023 & 3.21 & 0.08 \\
S3 & 2.52 & 0.029 & 6.36 & 0.14 \\
S4 & 3.14 & 0.031 & 9.89 & 0.19 \\
\hline
\end{tabular}

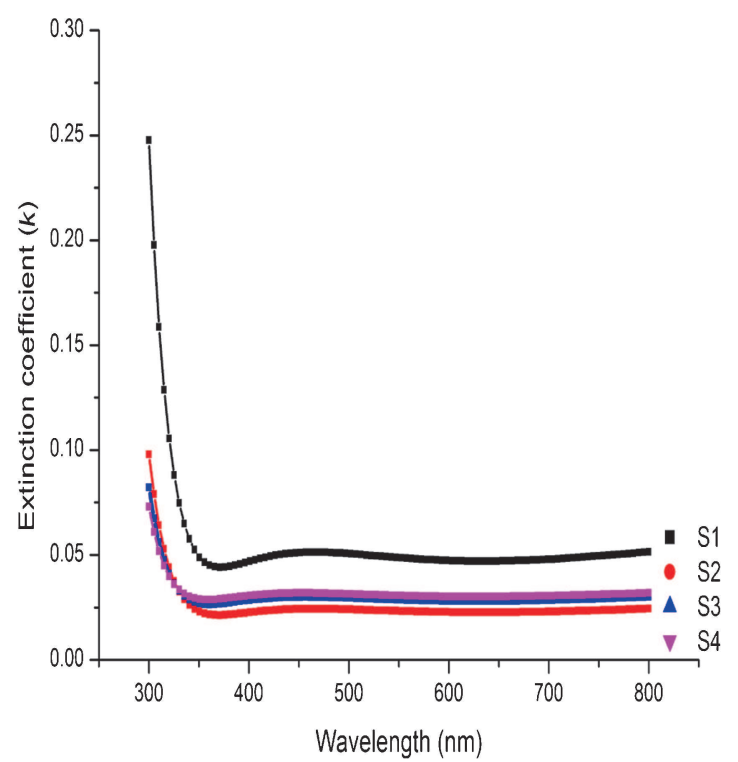

Figure 4. The dependence of the refractive index and extinction coefficient of the thin films on the wavelength. 
surface or interface, both electronic and vibronic ones. The spectral response of the solid in an inelastic electron scattering experiment can be described within the framework of dielectric theory named energy loss function. ${ }^{61}$ Energy loss function has a valuable role to investigate different aspects of materials. It has the advantage of covering the complete energy range including valance interband transitions and core level excitations. ${ }^{62}$ Two forms of energy loss function are usually interested, volume energy loss function (VELF) and surface energy loss function (SELF)

$$
\begin{aligned}
& \mathrm{VELF}=-\operatorname{Im}\left(\frac{1}{\varepsilon^{*}}\right)=\frac{\varepsilon_{2}}{\varepsilon_{1}^{2}+\varepsilon_{2}^{2}} \text { and } \\
& \mathrm{SELF}=-\operatorname{Im}\left(\frac{1}{\varepsilon^{*}+1}\right)=\frac{\varepsilon_{2}}{\left(\varepsilon_{1}+1\right)^{2}+\varepsilon_{2}^{2}} .
\end{aligned}
$$

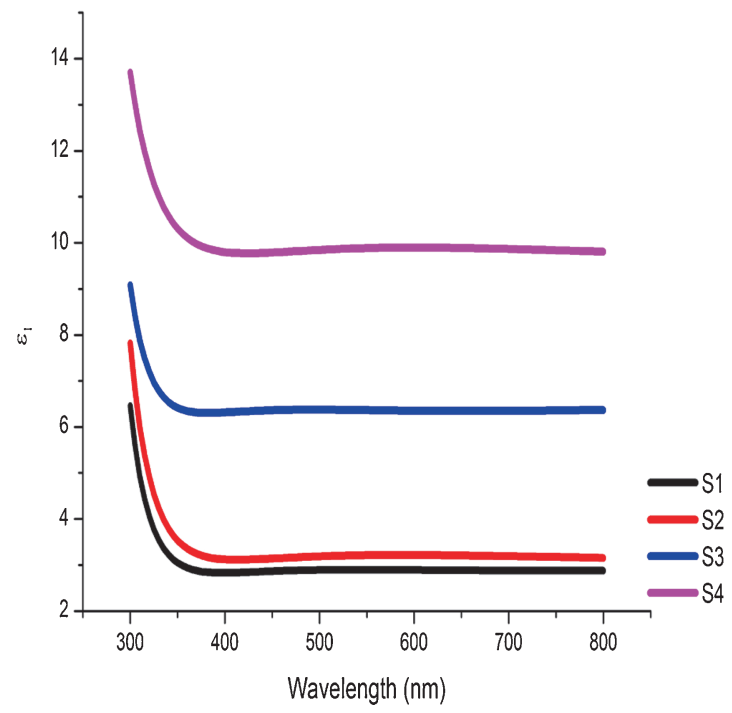

These quantities were estimated using real and imaginary parts of the dielectric constant, and plotted against energy (figure 6). From the calculated results it is obvious that the energy loss of the charge carriers when traversing through the bulk material has fairly the same behavior as when they traverse the surface. Although, it is clear that the VELF has a higher value than the SELF.

The energy loss spectrum of the low energy loss region typically $0-100 \mathrm{eV}$ reflects collective electron excitations (plasmons) and single valence-electron excitations into unoccupied states of the conduction band. Hence, electron energy loss in the low energy loss range is sensitive to the valence and conduction band structures. ${ }^{63}$

What is noteworthy for both, is a decrease trend of volume and surface energy loss amount, namely with approaching

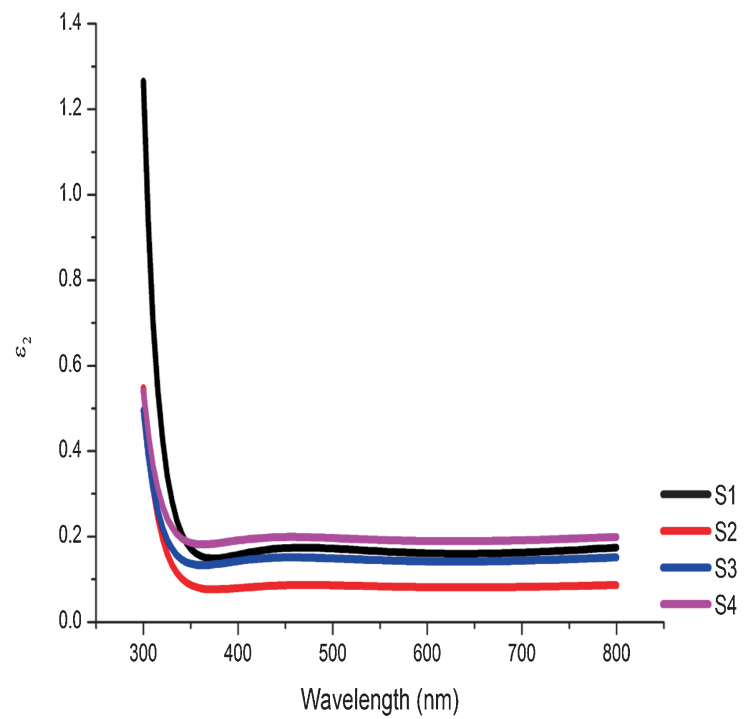

Figure 5. The variation of real and imaginary parts of the dielectric constant with wavelength.
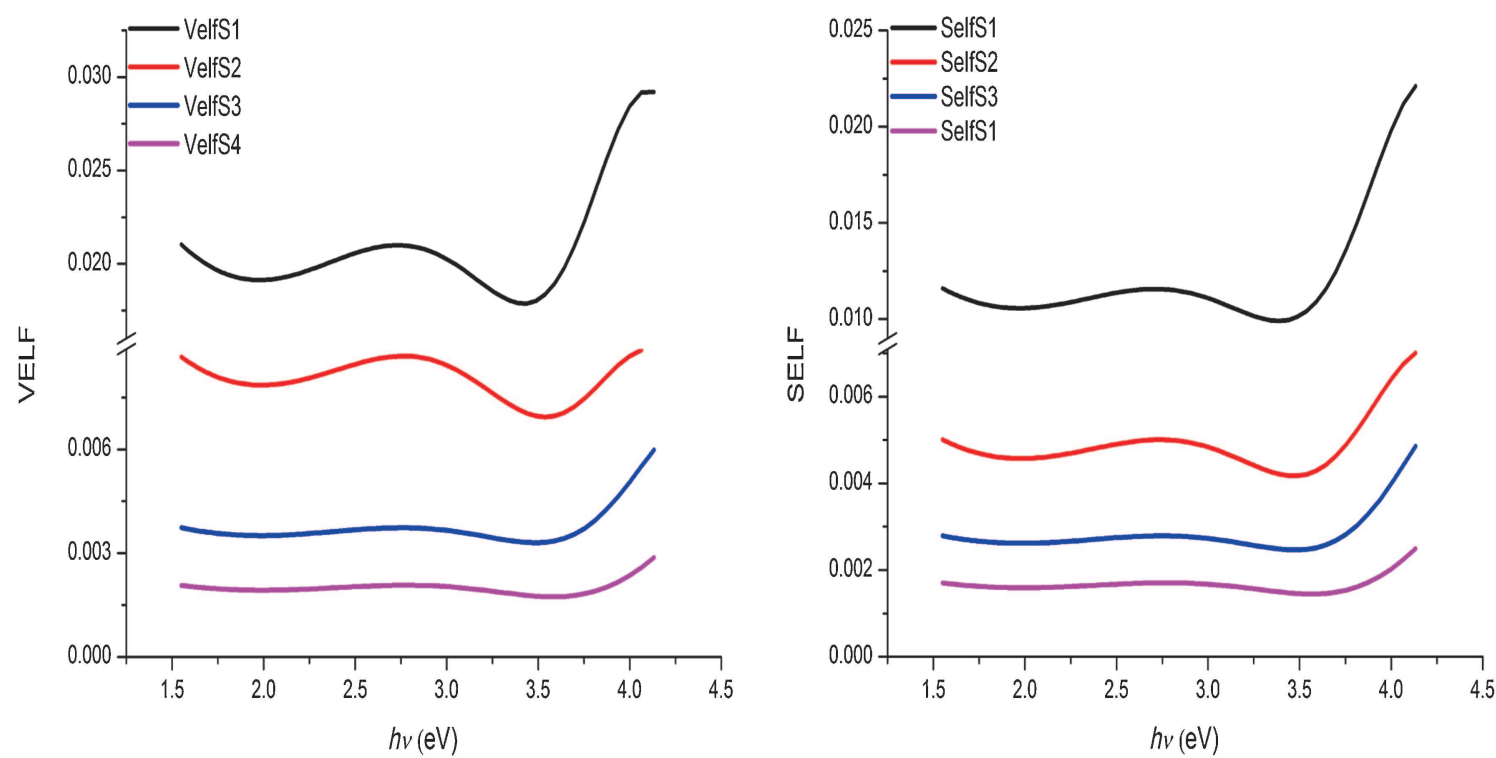

Figure 6. Plots of VELF and SELF vs. energy for thin films. 
the more nickel contribution the less loss is achieved which is favourable for special applications such as solar spectral selectivity.

The frequency dependence of dielectric reflects the fact that the polarization of a material does not respond to an applied field instantaneously. For this, the dielectric constant is often treated as a complex function of the frequency of the applied field. A perfect dielectric is a material that has no conductivity. However, the presence of dielectric loss inhibits the propagation of electromagnetic energy which aided conductivity. ${ }^{64}$

Optical conductivity is an interesting tool for studying the electronic states in materials. In general, by exerting an external electric field to a system, in general, a redistribution of charges occurs and currents are induced. The real part of optical conductivity can be determined by using the following relation: 65

$$
\sigma=\frac{\omega}{4 \pi}(\operatorname{Im}(\varepsilon))=\frac{\alpha n c}{4 \pi},
$$

where $c$ is the velocity of light, $\alpha$ the absorption coefficient and $n$ the refractive index.

Figure 7 shows the variation of optical conductivity $v s$. photon energy for thin films.

Figure 8 shows XRD patterns of thin films as a function of nickel content. The dominant amorphous nature of thin films especially in lower nickel content are obvious. But by increasing the ratio of nickel incorporation, some weak diffraction peaks appear. According to JCPDS no. 22-0451, there is rather good agreement between standard diffraction peaks of nickel aluminium oxide and our films. The relevant diffraction planes are marked into the diffraction curves. The amorphous structure of alumina in the temperature range below $550^{\circ} \mathrm{C}$ is ordinary $y^{5,66,67}$ even with doping material. ${ }^{68}$ Meanwhile the presence of nickel oxide characteristic peaks is reported at higher substrate temperature $\left(>350^{\circ} \mathrm{C}\right)^{1}$ and lower molarity $(<0.1 \mathrm{M}) .{ }^{10}$ Therefore, it seems alumina facilitate the presence of nickel oxide crystalline peaks at higher nickel content with lower substrate temperature and higher molarty. Although weak intensity peaks and polycrystalline structure is observed.

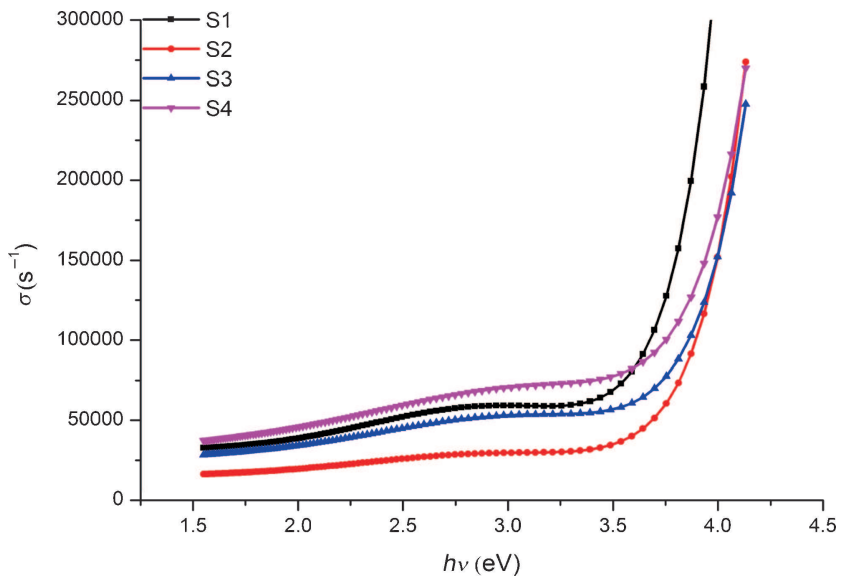

Figure 7. Plot of optical conductivity vs. photon energy.
Our electrical measurement also confirmed the role of alumina since at lower nickel content, there is not any electrical resistance whereas nickel oxide has a semiconductor property against the dielectric property of alumina.

The SEM micrographs of thin films in different nickel contents are shown in figure 9. Generally speaking, based on the micrographs, all samples have similar microstructures. Although all of the micrographs consist of nanosized grains but by increasing the nickel content, rather obvious spherical grains are observed. According to our previous experiment, ${ }^{41,42}$ alumina seems to have a spongy structure that establishes an appropriate status to infiltrate other elements such as a nickel.

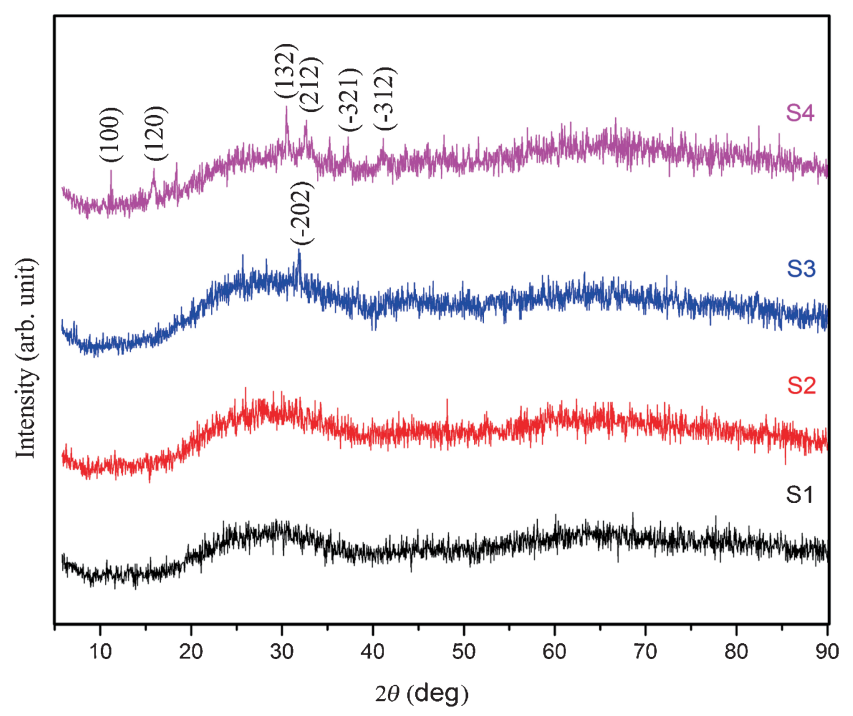

Figure 8. X-ray diffraction pattern of thin films.
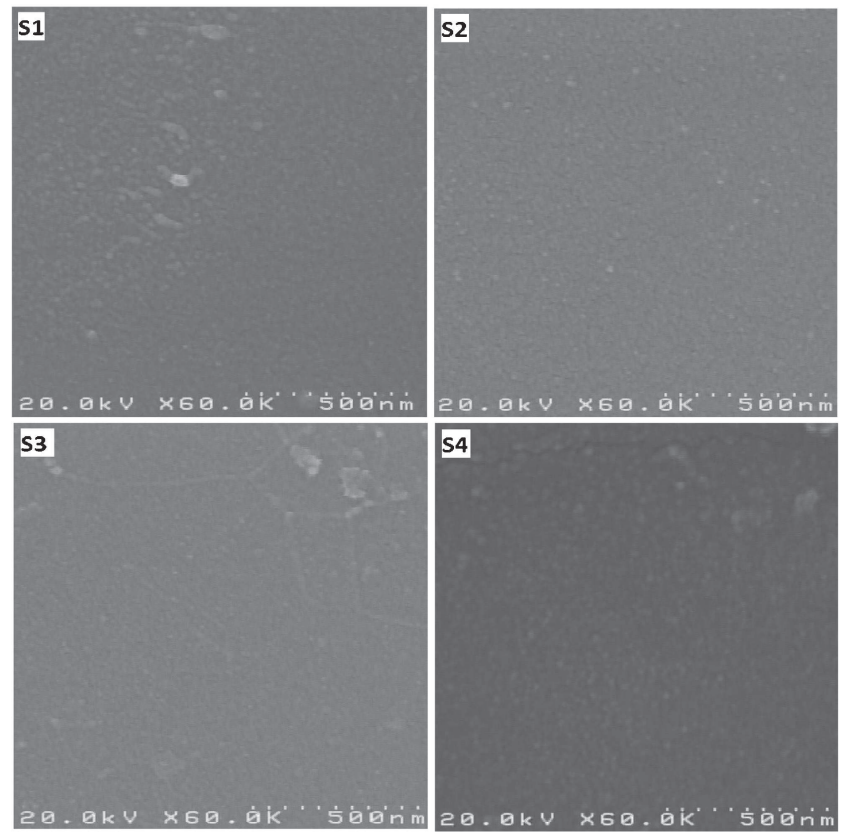

Figure 9. SEM images of thin films. 


\section{Conclusion}

The optical and morphological properties of aluminium and nickel oxide thin films deposited on glass substrate by spray pyrolysis have been investigated. The effects of different ratios of nickel content were compared. The optical transmittance of the films decreased from $60 \%$ (S1) to $24 \%$ (S4) at $550 \mathrm{~nm}$ for various nickel ratios and our observations also exhibited a relevant increase trend for absorptance values. The values of the optical band gap varied between 3.65 and $3.93 \mathrm{eV}$ for different films which comprised an increase trend. The refractive index and the extinction coefficient of the samples were also determined. The refractive index values have been varied between 1.70 and 3.14 and the extinction coefficient have been changed between 0.049 and 0.031 for the various samples. The real and imaginary parts of dielectric constants had analogous behaviour with corresponding complex refractive index because of their physical relations. In addition to the higher values of volume energy loss function than surface energy loss, a relative decrease in both due to nickel increase was also observed. According to XRD data, despite the overcoming amorphous nature of alumina especially in lower nickel content, when increasing nickel content, some weak diffraction peaks were appeared which were in good agreement with nickel aluminium oxide structure. However, a polycrystalline structure was formed. Although, similar micrographs were obtained by the SEM analysis, rather obvious nanosized spherical grains were developed by increasing the nickel content.

\section{Acknowledgement}

We gratefully acknowledge the research department of University of Guilan.

\section{References}

1. Mahmoud S A, Alshomer S and Tarawnh M A 2011 J. Mod. Phys. 21178

2. Isac L, Duta A, Purghel E, Chitanu G C, Mitrea S and Pelin I 2008 Phys. Status Solidi A 2052413

3. Pradhan S K, Reucroft P J and Ko Y 2004 Surf. Coat. Technol. 176382

4. Bostrom T, Westin G and Wackelgard E 2007 Sol. Energ. Mater: Sol. C 9138

5. Shamala K S, Murthy L C S and Narasimha Rao K 2007 Mater. Sci. Eng. B-Adv. 106269

6. Shamala K S, Murthy L C S, Radhakrishna M C and Narasimha Rao K 2004 Sens. Actuators. A-Phys. 135552

7. Avci N, Smet P F, Lauwaert J, Vrielinck H and Poelman D 2011 J. Sol-Gel Sci. Technol. 59327

8. Lebedev M and Krumdieck S 2008 Curr. Appl. Phys. 8233

9. Fortunato E, Barquinha P and Martins R 2012 Adv. Mater. 24 2945

10. Ismail R A, Ghafori S and Kadhim G A 2013 Appl. Nanosci. 3 509
11. Hotovy I, Huran J, Janik J and Kobzev A P 1998 Vacuum 51 157

12. Azens A, Kullman L, Vaivars G, Nordborg H and Granqvist C G 1998 Solid State Ionics 113-115 449

13. Shin W and Murayama N 2000 Mater. Lett. 45302

14. Guziewicz M, Grochowski J, Borysiewicz M, Kaminska E, Domagala J Z, Rzodkiewicz W, Witkowski B S, Golaszewska K, Kruszka R, Ekielski M and Piotrowska A 2011 Opt. Appl. 41431

15. Mathiyan J, Sivalingam D, Golpalakrishnan J B and Rayappan J B B 2012 J. Appl. Sci. 121686

16. Ohta H, Kamiya M, Kamiya T, Hirano M and Hosono H 2003 Thin Solid Films 445317

17. Rong X, Xin W, Delong J, Junqiao L, Guozheng W, Ye L, Qingduo D and Jingquan T 2010 Chin. J. Electron. 19631

18. Shaigan N, Ivey D G and Chen W 2009 J. Electrochem. Soc. 156 B 765

19. Cerc Korosec R, Bukovec P, Pihlar B, Surca Vuk A, Orel B and Drazic G 2003 Solid State Ionics 165191

20. Fantini M and Gorenstein A 1987 Sol. Energ. Mater. Sol. C 16 487

21. Sasi B and Gopalchandran K G 2007 Nanotechnology 18 115613

22. Kamel H, Elmaghraby E K, Ali S A and Abdel-Hady K 2005 Thin Solid Films 483330

23. You Y, Ito A, Tu R and Goto T 2010 Appl. Surf. Sci. 2563906

24. Vargas Garcia J R, Lazcano Ugalde E M, Hernandez Santiago F and Hallen Lopez J M 2008 J. Nanosci. Nanotechnol. 82703

25. Dhonge B P, Mathews T, Tripura Sundari S, Thinaharan C, Kamruddin M, Dash S and Tyagi A K 2011 Appl. Surf. Sci. 258 1091

26. Romero R, Martin F, Ramos-Barrado J R and Leinen D 2010 Thin Solid Films $\mathbf{5 1 8} 4499$

27. Thompson D W, Snyder P G, Castro L, Yan L, Kaipa P and Woollam J A 2005 J. Appl. Phys. 97113511

28. Patel K J, Panchal C J, Desai M S and Mehta P K 2011 J. Nano-Electron. Phys. 3362

29. Tang X, Luo F, Ou F, Zhou W, Zhu D and Huang Z 2012 Appl. Surf. Sci. 259448

30. Valyukh I, Green S, Arwin H, Niklasson G A, Wäckelgård E and Granqvist C G 2010 Sol. Energ. Mater. Sol. C 94724

31. Gianneta V, Nassiopoulou A G, Krontiras C A and Georga S N 2008 Phys. Status Solidi C 53686

32. Shrestha N K, Yang M and Schmuki 2010 P Electrochem. Solid-State Lett. 13 C21

33. Wang T, Pu J, Bo C and Jian L 2010 Fusion Eng. Des. 851068

34. Al-Ghamdi A A, Mahmoud W E, Yaghmour S J and Al-Marzouki F M 2009 J. Alloys Compd. 4869

35. Di Fonzo F, Tonini D, Bassi A L, Casari C S, Beghi M G, Bottani C E, Gastaldi D, Vena P and Contro R 2008 Appl. Phys. A-Mater. 93765

36. Wang H, Wang Y and Wang X 2012 Electrochem. Commun. 1892

37. Eun Kim C and Yun I 2012 Appl. Surf. Sci. 2583089

38. Yang T S, Cho W, Kim M, An K S, Chung T M, Kim C G and Kim Y 2005 J. Vac. Sci. Technol. A 231238 
39. Golshahi S, Rozati S M, Botelho do Rego A M, Wang J, Elangovan E, Martins R and Fortunato E 2013 Mater. Sci. Eng. $B-A d v .178103$

40. Patil G E, Kajale D D, Chavan D N, Pawar N K, Ahire P T, Shinde S D, Gaikwad V B and Jain G H 2011 Mater. Sci. B 341

41. Bagheri Khatibani A, Rozati S M and Hallaj Z A 2013 Mater. Sci. Semicond. Proc. 16980

42. Bagheri Khatibani A and Rozati S M 2013 J. Non-Cryst. Solids 363121

43. Birgin E G, Chambouleyron I and Martinez J M 1999 J. Comput. Phys. 151862

44. Heavens O S 1991 Optical properties of thin films (New York: Dover)

45. Swanepoel R 1983 J. Phys. E. Sci. Instrum. 161214

46. Ienei E, Isac L and Duta A 2010 Rev. Roum. Chim. 55161

47. Liu F, Lai Y, Liu J, Wang B, Kuang S and Zhang Zh $2010 \mathrm{~J}$. Alloys Compd. 493305

48. Bostrom T K and Wackelgard E 2006 J. Phys.: Condens. Mater. 187737

49. Lv X S, Deng Z H, Miao F X, Gu G X, Sun Y L, Zhang Q L and Wan S M 2012 Opt. Mater. 341451

50. Dahshan A 2009 Opt. Mater. 32247

51. Petkova P 2011 Opt. Mater. 34265

52. Moser F and Urbach F 1956 Phys. Rev. 1021519

53. Ilican S, Caglar M and Caglar Y 2007 J. Optoelectron. Adv. Mater. 91414

54. Yakuphanoglu F, Arslan M and Yildiz S Z 2005 Opt. Mater. 27 1153
55. Mulato M, Chambouleyron I, Brigin E G and Martinez J M 2000 Appl. Phys. Lett. 772133

56. Xu W L, Chen H, Zheng M J, Ding G Q and Shen W Z 2006 Opt. Mater. 281160

57. Abdolahzadeh Ziabari A and Ghodsi F E 2011 J. Alloys Compd. $\mathbf{5 0 9} 8748$

58. Czichos H, Saito T and Smith L 2006 Handbook of materials measurement methods (Leipzig: Springer)

59. Nejati M R, Fathollahi V and Khalaji Asadi M 2005 Sol. Energy $\mathbf{7 8} 235$

60. Wolaton A K and Moss T S 1963 P. Phys. Soc. Lond. 81509

61. Luth H 2001 Solid surfaces, interfaces and thin films, $4^{\text {th }}$ ed (Berlin: Springer)

62. French R H, Mullejans H and Jones D J 1998 J. Am. Ceram. Soc. $\mathbf{8 1} 2549$

63. Samantaray C B, Sim H and Hwang H 2005 Appl. Surf. Sci. 242121

64. Arumanayagam T and Murugakoothan P 2011 J. Miner. Mater. Charact. Eng. 101225

65. Ugwu E I, Olayinka A S and Olabode F I 2009 J. Eng. Appl. Sci. 4126

66. Guzman Mendoza J, Garcia Hipolito M, Aguilar Frutis M, Falcony C 2004 J. Mater. Sci-Mater. Electron. 15629

67. Bagheri Khatibani A and Rozati S M 2014 Mater. Sci. Semicond. Proc. 1880

68. Martinez E, Garcia M, Ramos-Brito F, Alvarez-Fregoso O, Lopez S, Granados S, Chavez-Ramirez J, Martinez R and Falcony C 2000 Phys. Status Solidi B 220677 